\title{
COULD BE CREATIVE ECONOMY AN ARGUMENT FOR GAINING EUROPEAN CAPITAL OF CULTURE STATUS? - COMPARATIVE ANALYSIS BETWEEN ROMANIAN CITIES CANDIDATE
}

DOI: http://dx.doi.org/10.18509/GBP.2020.33

UDC: 332.1:711.45]:303.71(498)"2000/2018"

\author{
Radu-Daniel Pintilii ${ }^{1,2}$ \\ Marian Marin ${ }^{1,2}$ \\ Andreea Karina Gruia ${ }^{1,2}$ \\ Alexandra Grecu ${ }^{1,2}$ \\ Bogdan Teriș ${ }^{1,2}$ \\ ${ }^{1}$ University of Bucharest-Research Center for Integrated Analysis and Territorial Management; \\ Bucharest, Romania \\ ${ }^{2}$ Faculty of Geography, University of Bucharest, Bucharest, Romania
}

\begin{abstract}
Creative economy plays an important role in the development of local communities and regions. They also have a great polarization capacity, generating multiplying effects. The present study makes a comparative analysis between the main Romanian cities that candidate for gaining the status of European Capital of Culture, for 2020. These cities that compete for this title were Bucharest (the Capital City), Timișoara, Cluj-Napoca, Iași and Baia Mare. Among these Timișoara has been chosen for gaining this status. The methodology is based on the study of some indicators (number of companies, employees and the value of profit and turnover) belonging to the creative economy field. The data used are at 4-digit level NACE codes and will also analyse the impact on its dynamic from 2000 to 2018. The main softwares used will be the GIS and RStudio platforms. The main results will consist on some graphics and cartographic representation of the territorial distribution of the creative economy. Our analysis identified the strengths of the local creative economy in the city of Timisoara, which allowed it to obtain the title of European Capital of Culture.
\end{abstract}

Keywords: creative economy, European capital of culture, analysis, Romania

\section{INTRODUCTION}

The concept of the Capital of European Culture aims to generate a revival of regional culture after a period of decline. Each city candidate for this title tries to offer the public that pride that defines it. Buildings - architecture can be a solid argument, but it certainly adds to the natural context. The status of cultural capital offers to the candidate cities opportunities for further development, especially through the urban regeneration process - revitalization of buildings with significance, artifacts of the periods of industrial, economic development.

Since 1990, until now, there has been talk within the regional economic policies about solutions such as clusters, the creative class - creative industries or high-tech industries. At present, a new concept is emerging, that of the entrepreneurial ecosystems. These are viewed as disinhibiting factors of growth and development potential within cities or regions [1]. 
The implications of multiculturalism play an important role in defining public policies. Therefore, in the case of candidate cities or holders of the title of capital of European culture, urban intercultural indicators must be considered. They are found in the three dimensions of local cultural policies - discourse, governance and cultural content.

Creative economies contribute to establishing the partnership between local public authorities, minorities and newcomers in the city. As such, the Council of Europe also emphasizes the continuous involvement of urban actors, because both minorities and newcomers have economic potential.

The cultural content of such a process and especially its size, analyzes the level and intensity of multicultural and intercultural relations. From this perspective, the activities of the creative economy are oriented towards knowledge, towards the development of the capacities of understanding and acceptance of cultural differences [2].

Cities and regions are increasingly using events to drive economic growth. The concept of Capital of European Culture promotes urban management and economic production through culture, using social heritage and creating new jobs [3], [4], [5]. It becomes essential for these cities to assume in the long term a creative economy, strategically placed and competitive, in order to strengthen the urban and regional capacity in supplying different products. It is important to point out that EU policy is trying to contribute to increasing the standard of living at regional level [6] and reducing disparities. That is why the activities associated with a cultural capital manifest their regional influence, having a multiplier effect [7], [8].

Charles Landry in his work [9] highlights the existence of cultural factors that trigger the processes and ideas that cities generate through the creative economy. Whether it is new discoveries, new opportunities, entrepreneurship, competitiveness, creative activities are almost indispensable in their emergence. Robert Florida's arguments for the role of the creative economy have highlighted that growth is generated by the creative, talented class, who prefer ethnically diverse spaces, tolerance, their concentration generating processes and products, technology [10].

Major cultural events are considered by local economic actors as important opportunities in stimulating economic development, in creating city branding and in supporting urban regeneration. The stages identified in the valorization from the perspective of the status of the cultural capital include: conceptualization and operationalization of the culture, regeneration and urban rebranding and creation of mythical spaces; hygiene of the aspects celebrated by the local culture; the ability of cultural strategies to provide economic growth and social inclusion, involving residents in solving the problems of disadvantaged communities. Being creative, the concept of culture refers to people and how they get to interpret their own environment, local flavor and value systems. The politicization of culture through the Capital of European Cut must have as an aim to increase the visibility and attractiveness of the city at national, European and global level [11].

This statute must trigger a profound change in the economic policy of the city, in the modification of the relations between center and periphery. The challenges of such an approach are related to the tensions between the actors involved in the creation of a salable product and the existing social reality. Culture as a factor of development must cause and not reproduce social, cultural or economic inequalities [12].

The increase of the political dimension of the cultural sphere has been accompanied by confusions regarding the terminology. Thus, the notion of arts became a cultural sector, the cultural sector later became a cultural industry and the cultural industries became creative industries. The exaggeration of the role of cultural resources in favoring the 
"creative city" [9] or the critical place that the "creative class" occupies in the rebirth of urban economies [13] have been included in the urban rhetoric of political decisionmakers without any critical. In each candidate city there were several imaginative projects during the application formulation, to encourage participation and generation of ideas, which otherwise would not have occurred [14].

\section{METHODOLOGY}

The study area of the present study are the four cities of Romania, that candidate for gaining the status of the European Capital of culture. Among them, Bucharest (the capital city of Romania), Timișoara, Cluj-Napoca and Baia-Mare. All the last three cities are county capital, playing an important administrative role, too. The data base used, contains the number of companies and the employees, analysed in their evolution and structure, both at country level and the creative economy sector. The data are at 4digit NACE code for each economic activity.

\section{RESULTS}

As can be seen from the graph (Figure 1), the companies in the creative field are on an upward trend. A period of beginning (2000-2007) in which the creative activities develop organically, is followed by a period of constant growth, we could say even sustainable, considering the annual figures. The situation can be argued by increasing the attractiveness for foreign investments, important actors of the IT sector, relocating some of the activities in Romania.

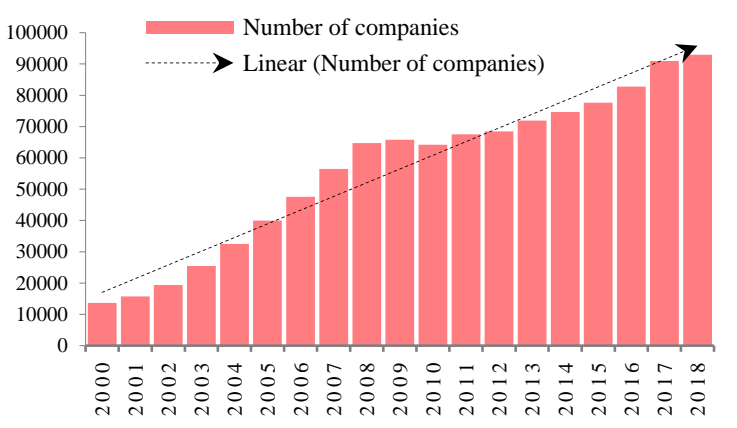

Figure 1. Number of companies in creative sector (Romania)

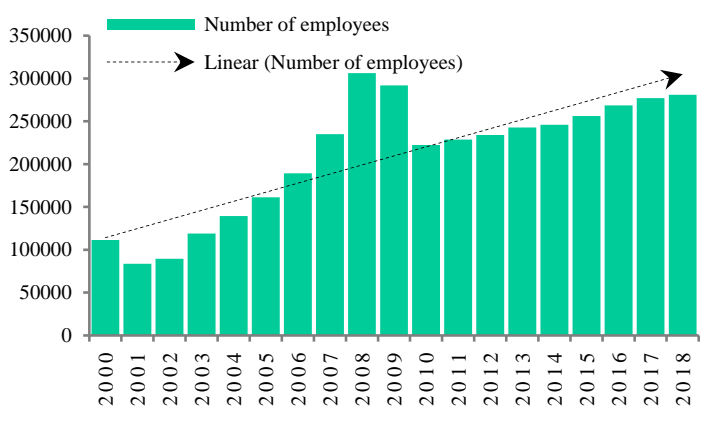

Figure 2. Number of employees in creative sector (Romania)

Source: Project UB 1423

Trend regarding no. of companies was increasing until 2008, when the economic crisis generates a recession, which manifested itself until 2013. From this moment until 2018 we are witnessing an increase of number of companies, at the same time with the stabilization and consolidation of the existing ones. The growth was substantial, number of companies in 2018 being almost 8 times higher than the no. since 2000 .

Regarding no. of employees, we can observe a significant growth in the period 2000-2008 (Figure 2), with an absolute peak (for the whole period analyzed) in 2008. There follows a period of decline that overlaps the economic crisis, no. of employees falling in 2012 below the level registered in 2007. From 2013 the upward trend starts again, but in 2018, the 2008 level is not reached.

As can be seen in 2018, the highest share, 55\% is held by the knowledge-high tech sector, followed by the information-communications sector, 14\%, which together with the 6 
percent of education, can be argued by the center status. university of the city. Cultural and recreational activities capitalize on the rich, diverse cultural, material and immaterial heritage. It is worth mentioning the presence in this territorial system of some emblematic tourist regions, Maramureș Country, Lăpuș Country (Figure 3 and 4). The multicultural context, which is a very powerful argument for obtaining the title of Capital of European Culture, must not be overlooked either.

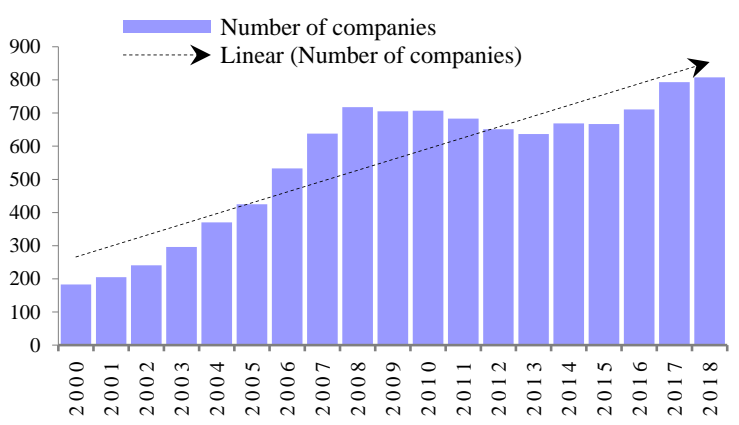

Figure 3. Evolution of companies in creative sector (Baia-Mare)

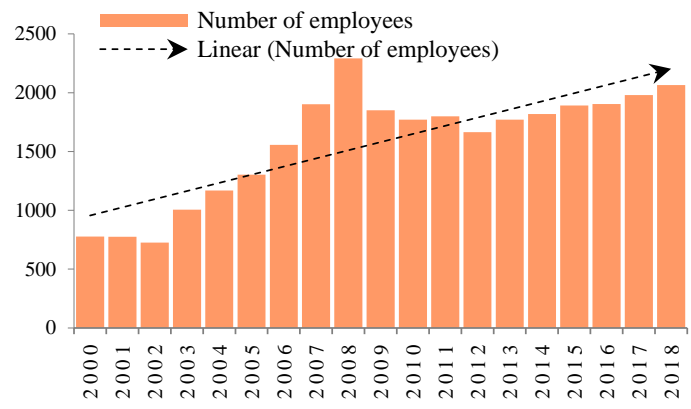

Figure 4. Evolution of employees in creative sector (Baia-Mare) Source: Project UB 1423

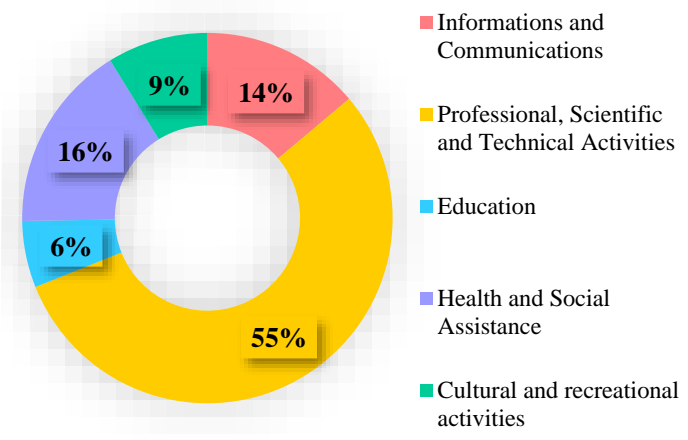

Figure 5. Structure of companies in creative sector (Baia Mare - 2018)

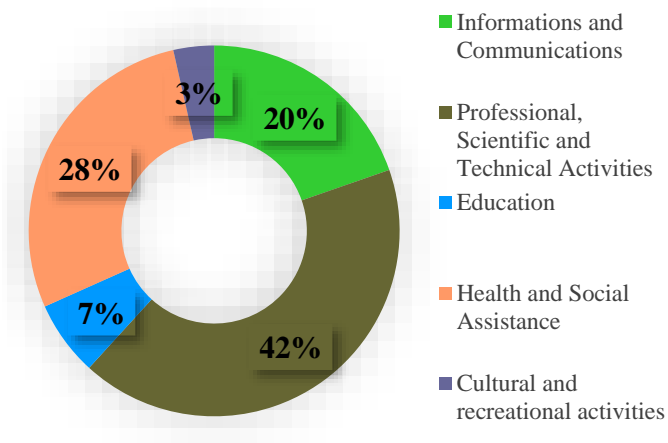

Figure 6. Structure of employees in creative sector (Baia Mare - 2018) Source: Project UB 1423

From the perspective of number of employees, the highest share is found in the knowledge-high tech sector, followed by the information and communications sector, health and social assistance, education and tourism (Figure 5 and 6). One explanation for this ranking would be that the economy of the territorial system has been forced to adapt to the migration of medium and low skilled labor to EU markets. Tourism and cultural activities are growing and represent two important options regarding the development process.

Bucharest is seconded in the ranking of creative cities in Romania (Figure 7 and 8). The arguments in this regard are the tradition regarding the higher education, the capital status of Romania, one of the most important cultural centers at national and regional level. The evolution no. of companies in the creative field followed an upward trend. There was a syncope in 2010, as a result of the economic crisis, but the territorial system quickly repositioned, and the growth continued. It must be taken into account the fact that Bucharest is the headquarters of important companies in the creative field (IT, media, 
architecture, etc.), having the advantage of international connectivity through the largest airport in Romania and providing the ultra-specialized workforce, represented by university graduates. from here.

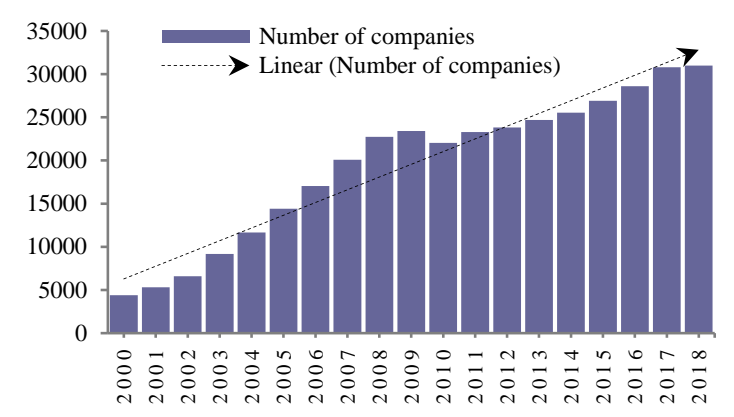

Figure 7. Evolution of companies in creative sector (Bucharest)

Source: Project UB 1423

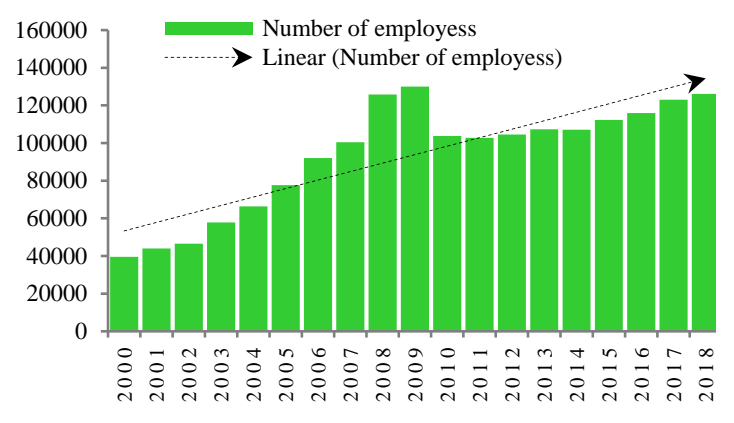

Figure 8. Evolution of employees in creative sector (Bucharest)

The time interval 2000-2009 is noted by a constant increase of number of employees in the creative field. In 2010 we are witnessing a sharp decline, after which the upward trend is maintained until 2018, without reaching the value of 2009. The fact that the turnover for 2008-2010 has been relatively constant, means that the adjustments made to make in the face of the crisis, they focused exclusively on the workforce.

From the perspective of the structure of the creative field, there is a clear positioning of the high-tech-knowledge sector, primarily due to the increased visibility of the city of Bucharest in the IT field and the provision of technological solutions (Figure 9 and 10). The second position is occupied by the information and communications sector, here the argument being the HUB status of communications of the capital of Romania. The private initiative in the medical field and the social assistance system is largely reflected by the 15\%. Education and cultural and recreational activities have similar percentages, supporting overall the relevance of the creative field in the context of the urban economy.

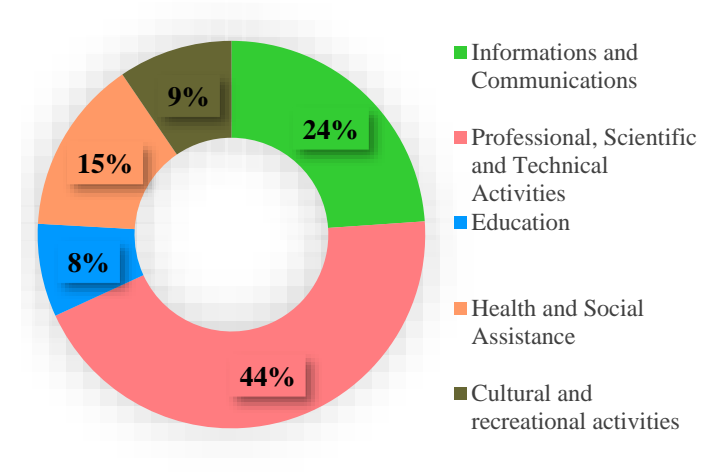

Figure 9. Structure of companies in creative sector (Bucharest - 2018)

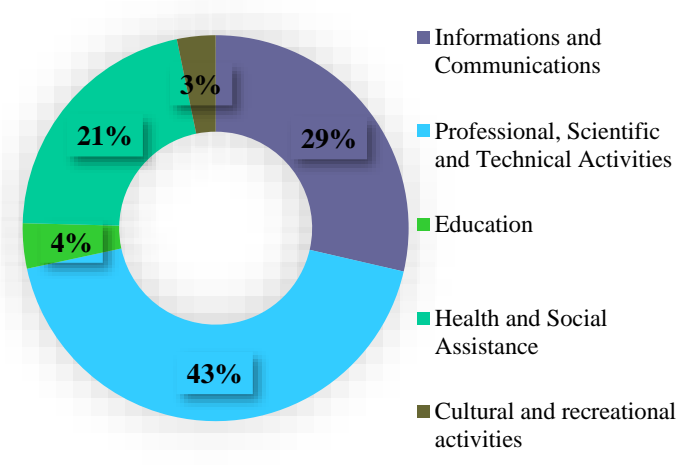

Figure 10. Structure of employees in creative sector (Bucharest - 2018)

Source: Project UB 1423

As a structure of the workforce, the creative field proposes a distribution with a dominant position in the knowledge-high tech sector, followed by information and communications, health and social assistance and education and cultural and recreational activities. 
The evolution of the number of companies in the creative field for the city of ClujNapoca, follows an upward trend with a constant evolution until 2009 (Figure 11 and 12). In 2010 it was a time of regression, after which 2011 has regained its ascent, something more spectacular between 2015-2018.

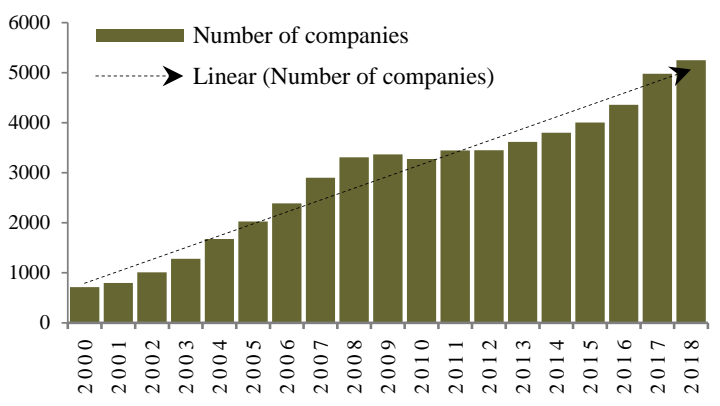

Figure 11. Evolution of companies in creative sector (Cluj-Napoca)

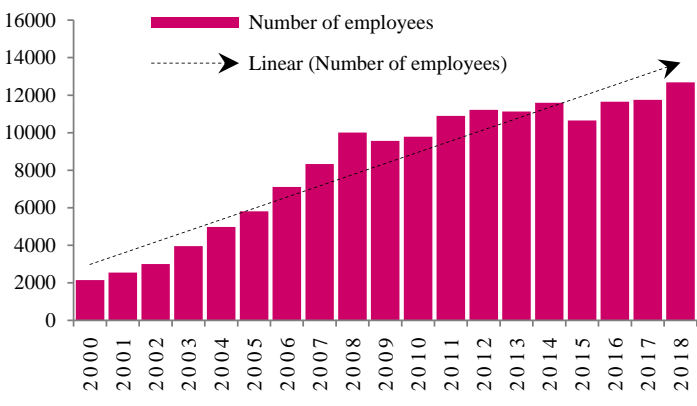

Figure 12. Evolution of employees in creative sector (Cluj-Napoca)

Source: Project UB 1423

The number of employees is marked by two periods of decline, 2008-2009 (economic crisis) and 2014-2015 9 reorganization of the knowledge - high tech sector. From 2016 number of employees grows, spectacular in 2018 (Figure 13).

As in the case of Bucharest and the city of Cluj-Napoca, there is a dominant position in the sector of the knowledge-high tech list (47\%), followed at a great distance by the field of information and communications (19\%), health and social assistance (17\%), education and cultural and recreational activities (Figure 14).

Like number of employees, the knowledge-high tech sector is in first position, followed by information and communications, health and social assistance, cultural and recreational activities and education.

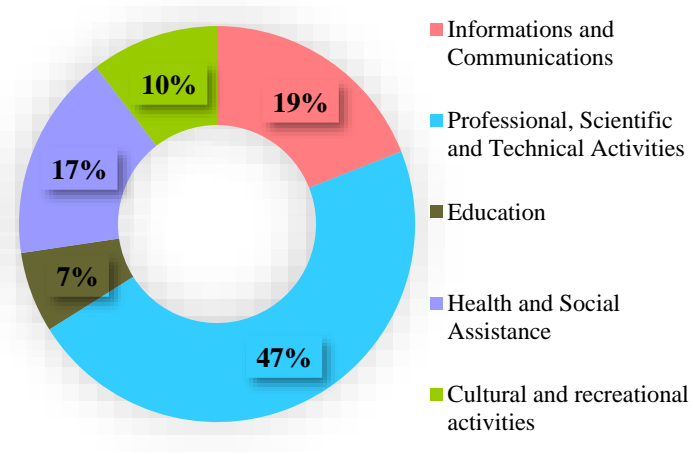

Figure 13. Structure of companies in creative sector (Cluj-Napoca - 2018)

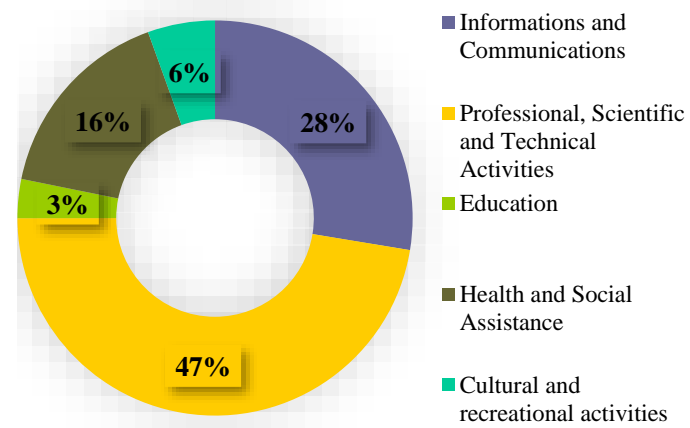

Figure 14. Structure of employees in creative sector (Cluj-Napoca - 2018)

Source: Project UB 1423

In the case of Timisoara, the upward trend of evolution no. of companies in the creative field is marked by a somewhat constant stagnation period between 2008-2012, probably due to the crisis (Figure 15 and 16). It is interesting because compared to the other competitors (less Bucharest), which registered decreases, Timisoara kept its capital in this regard. Certainly, the multicultural background of the city, the very diverse cultural landscape and the bidder managed to support the creative field. 


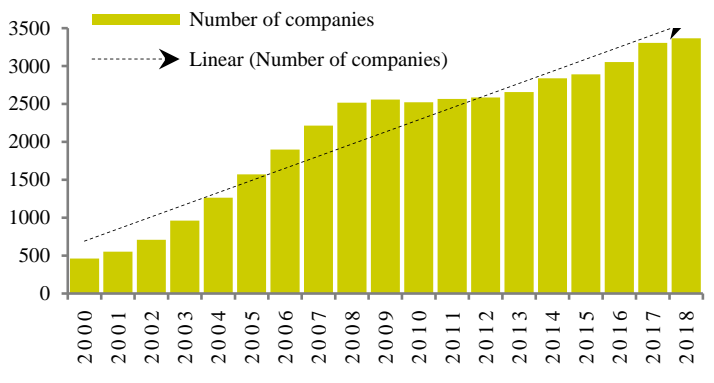

Figure 15. Evolution of companies in creative sector (Timişoara)

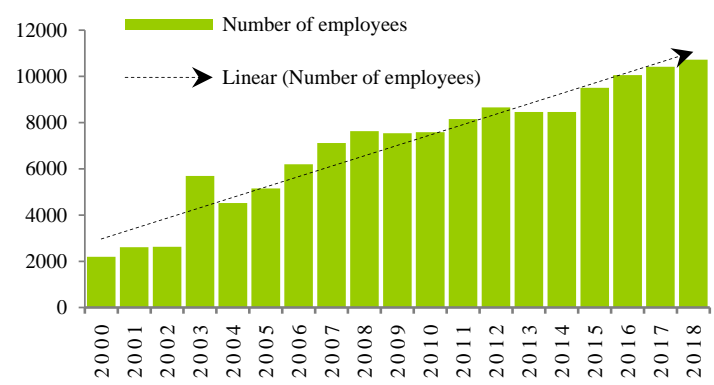

Figure 16. Evolution of employees in creative sector (Timișoara)

Source: Project UB 1423

And in the case of evolution number employees can talk about the same features as in case no. of companies and turnover, namely that between 2008-2010 we are witnessing a stagnation rather than a decrease of this number. Between 2012-2013, the decrease manifests itself without significantly affecting the evolution.

The first place in terms of the structure of companies in the creative field is occupied by the activities of the knowledge-high tech sector. The second place, at a distance, $25 \%$ is occupied by the health and social assistance sector. It is worth noting in this regard the increase of the role of private initiatives in this field, supported by the role that Timisoara has in the field of medical tourism (proximity to the states of Central Europe, low prices of medical services). In the third place is the information and communications sector (another specificity compared to the other competitors) the last two places being occupied by culture and recreational and education activities (Figure 17 and 18).
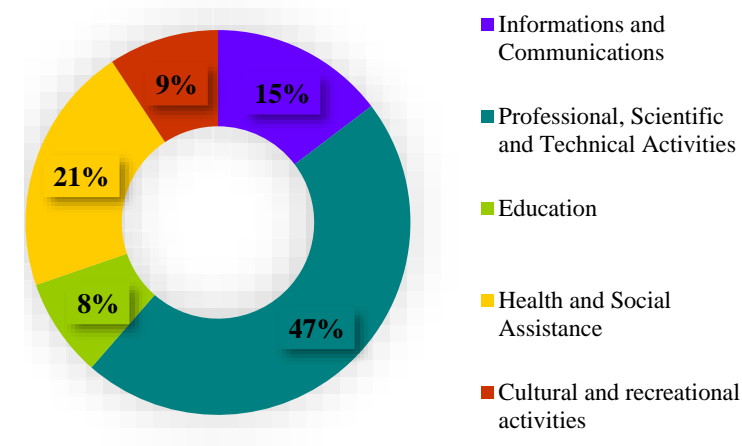

Figure 17. Structure of companies in creative sector (Timisoara - 2018)

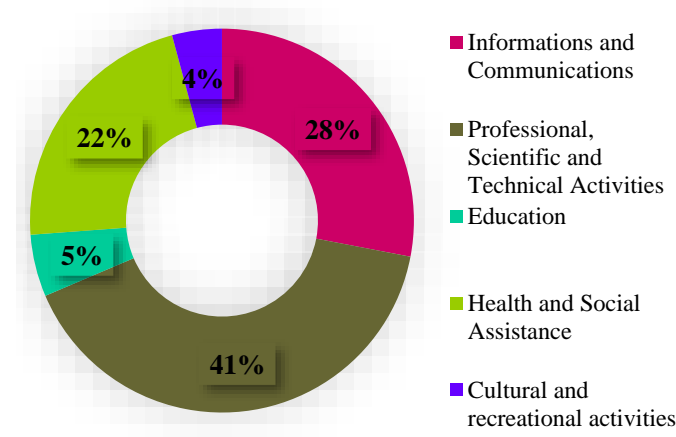

Figure 18. Structure of employees in creative sector (Timisoara - 2018)

Source: Project UB 1423

As structure according to no. of employees, the ranking is changed by exchanging places between the information and communications sector (position 2) and health and social assistance (position 3). The last two positions and these reversed, are occupied by education and culture and recreational activities.

\section{CONCLUSIONS}

The first decade of the 2000s is marked by a gradual increase, situation influenced by the relocation, repositioning and reconversion of the Romanian economy. Processes in which the creative economy activities have provided, in some cases, opportunities for the 
available labor force from other sectors of activity. The 2007-2009 interval is marked by a spectacular growth superimposed on the economic growth at national level, an increase based mainly on consumption.

The crisis period, the year 2010, illustrates a decrease of no. of employees of the creative economy below the level of 2008. This dramatic decrease was followed by a constant growth, the upward trend being maintained until the end of the analyzed period.

\section{REFERENCES}

[1] Sternberg R., Von Bloh J. \& Coduras A. A new framework to measure entrepreneurial ecosystems at the regional level, De Gruyter, Lancaster University, 2019.

[2] Campagna D. \& Jelinčić D. A. A Set of Indicators of Interculturalism in Local Cultural Policies, HKJU-CCPA, vol. 18, pp 47-71, 2018.

[3] Richards G., de Brito M.P. \& Wilks L. (eds) Exploring the Social Impacts of Events. London: Routledge, 2013.

[4] Richards G. \& Wilson J. The impact of cultural events on city image: Rotterdam, cultural capital of Europe 2001, Urban Studies, vol. 41, pp 931-1951, 2007.

[5] Spirou C. Urban Tourism and Urban Change, London: Routledge, 2011.

[6] Forte A., Tortosa-Ausina J. \& Peiro-Palomino E. Does social capital matter for European regional growth?, European Economic Review, vol. 77, pp 47-64, 2015.

[7] Aquilino L., Armenski T. \& Wise N. Assessing the competitiveness of Matera and the Basilicata Region (Italy) ahead of the 2019 European Capital of Culture, Tourism and Hospitality Research, pp 1-15, 2018.

[8] Pintilii R.D., Peptenatu D., Draghici C., Saghin I. \& Stoian R.D. Structural Changes in The Entrepreneurial Profile of The Creative Industries in Romania, 2nd Global Conference on Business, Economics, Management and Tourism, Czech Republic, 2015, pp 1147-1151.

[9] Landry C. The Creative City: A Toolkit for Urban Innovators. London: Earthscan, 2000.

[10] Montgomery J. Beware 'the Creative Class'. Creativity and Wealth Creation Revisited. Local Economy, vol. 20, 2005.

[11] Boland, O. Capital of Culture-you must be having a laugh!' Challenging the official rhetoric of Liverpool as the 2008 European cultural capital, Social \& Cultural Geography, vol. 11, 2010.

[12] Jones P. \& Wilks-Heeg S. Capitalising culture: Liverpool 2008. Local Economy, vol. 19, pp 341-360, 2004.

[13] Florida R. The Rise of the Creative Class. New York: Basic Books, 2002.

[14] Griffiths R. City/Culture Discourses: Evidence from the Competition to Select the European Capital of Culture 2008, European Planning Studies, vol. 14, 2006. 